\title{
Meningiomas and schwannomas: Molecular subgroup classification found by expression arrays
}

\author{
VICTOR MARTINEZ-GLEZ ${ }^{1}$, CARMEN FRANCO-HERNANDEZ ${ }^{1}$, LUIS ALVAREZ ${ }^{1}$, JOSE M. DE CAMPOS ${ }^{2}$, \\ ALBERTO ISLA $^{3}$, JESUS VAQUERO ${ }^{4}$, LUIS LASSALETTA $^{5}$, CACILDA CASARTELLI $^{6}$ and JUAN A. REY ${ }^{1}$ \\ ${ }^{1}$ Unidad de Investigación, Hospital Universitario La Paz, Madrid; ${ }^{2}$ Servicio de Neurocirugía, \\ Fundación Jiménez Díaz, Madrid; ${ }^{3}$ Servicio de Neurocirugía, Hospital Universitario La Paz, Madrid; \\ ${ }^{4}$ Servicio de Neurocirugía, Hospital Puerta de Hierro, Madrid; ${ }^{5}$ Servicio de Otorrinolaringología, \\ Hospital Universitario La Paz, Madrid, Spain; ${ }^{6}$ Laboratorio de Oncogenética, Departamento de Genética, \\ Facultade de Medicina de Ribeirao Preto, Universidade de Sao Paulo, Ribeirao Preto, Sao Paulo, Brazil
}

Received September 17, 2008; Accepted November 3, 2008

DOI: 10.3892/ijo_00000174

\begin{abstract}
Microarray gene expression profiling is a highthroughput system used to identify differentially expressed genes and regulation patterns, and to discover new tumor markers. As the molecular pathogenesis of meningiomas and schwannomas, characterized by $N F 2$ gene alterations, remains unclear and suitable molecular targets need to be identified, we used low density cDNA microarrays to establish expression patterns of 96 cancer-related genes on 23 schwannomas, 42 meningiomas and 3 normal cerebral meninges. We also performed a mutational analysis of the NF2 gene (PCR, dHPLC, Sequencing and MLPA), a search for $22 \mathrm{q} \mathrm{LOH}$ and an analysis of gene silencing by promoter hypermethylation (MS-MLPA). Results showed a high frequency of NF2 gene mutations $(40 \%)$, increased $22 \mathrm{q} \mathrm{LOH}$ as aggressiveness increased, frequent losses and gains by MLPA in benign meningiomas, and gene expression silencing by hypermethylation. Array analysis showed decreased expression of 7 genes in meningiomas. Unsupervised analyses identified 2 molecular subgroups for both meningiomas and schwannomas showing 38 and 20 differentially expressed genes, respectively, and 19 genes differentially expressed between the two tumor types. These findings provide a molecular subgroup classification for meningiomas and schwannomas with possible implications for clinical practice.
\end{abstract}

Correspondence to: Dr Víctor Martínez-Glez, Unidad de Investigación, Hospital Universitario La Paz, Paseo Castellana 261, 28046 Madrid, Spain

E-mail: vmartinezg.hulp@salud.madrid.org.

Key words: microarray, gene expression, meningiomas, schwannomas, $N F 2$

\section{Introduction}

Meningiomas represent $\sim 20 \%$ of all primary intracranial tumors and arise sporadically or within the neurofibromatosis type 2 syndrome (NF2). Cytogenetically, the characteristic alteration is the partial or total loss of chromosome 22 (up to $70 \%$ ) (1). Other cytogenetic changes secondary to this anomaly are primarily the deletions of $1 \mathrm{p}$ and $14 \mathrm{q}$ (2). At the molecular level, half of these tumors have allelic losses including the $22 \mathrm{q} 12$ band. The NF2 gene, located at $22 \mathrm{q} 12.2$, is considered the main candidate for the genesis of meningiomas and works as a tumor suppressor gene (TSG). Mutations in this gene have been detected in $60 \%$ of meningiomas (3). NF2 has also been found silenced by promoter hypermethylation (4), although this has not been found in all cases (5). Other TSG epigenetically silenced in meningiomas include THBS1 (15-30\%), TIMP-3 (24\%), pl6(INK4a) (17\%), MGMT (6-16\%), p73 (15\%), ER (15\%), GSTP1 (27\%), RBI (10\%) and pl4(ARF) (13\%) (6,7). In addition, atypical and anaplastic meningiomas show frequent losses in chromosomal arms 1p, 14q, 6q, 9q, 10, 17p, 18p and $18 \mathrm{q}(1,8-10)$.

On the other hand, schwannomas are benign encapsulated tumors that grow around the nerves. Schwannomas also arise sporadically or within NF2 syndrome. NF2 is characterized by the presence of bilateral vestibular schwannomas at an early age (11). The main genetic alterations found in this tumor type are loss of heterozygosity $(\mathrm{LOH})$ of the long arm of chromosome 22 (up to $50 \%$ ) and the mutations in the NF2 gene (up to $60 \%)(12,13)$. Other cytogenetic gains, losses or alterations of specific genes vary $(12,14,15)$. Epigenetic silencing of the NF2 gene (18-60\%) has also been detected in schwannomas $(16,17)$. The relevance of aberrant $N F 2$ methylation with respect to tumor genesis in both tumor types remains to be clearly determined. As with meningiomas, aberrant promoter hypermethylation of other tumorrelated genes has also been described in schwannomas: THBS1 (30-36\%), TP73 (19-27\%), MGMT (16-20\%), TIMP-3 $(18 \%), R B 1 / p 16^{I N K 4 a}(15 \%)(16,18)$. For schwannomas and meningiomas it is considered that there might be other TSGs 
located at 22q, that could be involved in the development of these tumors, since deletions of $22 \mathrm{q}$ outside the $N F 2$ locus have also been reported (19).

The methods used to classify cancer are currently based on morphological characteristics. The information obtained by this method is limited and omits many tumor characteristics, such as the rate of proliferation, invasion and metastasis ability, and the possible development of cellular mechanisms of resistance to treatment $(1,20)$. Microarray gene expression profiling is a high-throughput system that can be used in combination with conventional diagnostic methods as a useful complement. In addition to the identification of differentially expressed genes and the establishment of gene expression patterns, microarrays can also allow us to discover potential tumoral markers that could improve clinical practice and therapy for cancer (21-23).

Currently there are few studies that have identified patterns of gene expression using microarrays in meningiomas or schwannomas (24-31). In this study we used low density microarray expression profiling in a series of schwannomas and meningiomas to find the differential expression of 96 genes specifically involved in: i) control of the cell cycle and damage to DNA repair; ii) apoptosis and cellular senescence, ii) signal transduction and transcription factors; iv) adhesion; v) angiogenesis; and vi) invasion and metastasis. We also performed correlations with the tumor grade, molecular alterations of the NF2 gene, $\mathrm{LOH}$ in $22 \mathrm{q}$ and the methylation status of 25 cancer-related genes, in order to identify molecular markers with diagnostic, prognostic and therapeutic potential.

\section{Materials and methods}

Sample and DNA/RNA preparation. Samples and clinicalpathological data were obtained according hospital ethical committee's procedures. DNA was isolated from 65 frozen samples, corresponding to 42 meningiomas and 23 schwannomas, using the Wizard Genomic DNA purification kit (Promega). DNA from the corresponding patients' peripheral blood was also extracted. RNA was isolated using the RNeasy ${ }^{\circledR}$ Mini Kit (Quiagen) and Poly A was obtained using the Oligotex ${ }^{\circledR}$ mRNA Mini Kit (Quiagen). Pathological diagnosis was performed according to the WHO classification (1), and included 32 grade I, 6 grade II, and 4 grade I recurrent meningiomas. As controls 3 commercial human adult normal RNA from cerebral meninges were used (USBiological Catalogs No T5595-7251, T5595-7252A and Biochain Catalog No R1234043-50-BC). No normal Schwann controls were available.

$22 q \mathrm{LOH}$. The allelic status of 5 microsatellite markers at the D22S275, D22S264, D22S929, D22S268 and D22S280 loci (22q11-q12.3) was determined by labeling 5' primers with fluorescent markers (6-FAM/HEX and ROX as a size standard, Applied Biosystems, Foster City, CA). Allelic ratios were defined according to previously described criteria: T2xN1/T1xN2 in which $\mathrm{LOH}<0.6-1.67>\mathrm{LOH}$ (32).

PCR/dHPLC analysis and direct sequencing of NF2. Genomic DNA amplification was performed by standard PCR methods (total volume of $20 \mu \mathrm{l}$ ). A set of 15 primer pairs were used as described (33). Mutational screening was carried out using dHPLC following manufacturer's protocols (Transgenomic WAVE ${ }^{\circledR}$ dHPLC Systems). Samples with abnormal patterns were sequenced bidirectionally (ABI 3100 Avant, Applied Biosystems), using the Big Dye sequencing kit (Applied Biosystems), to determine the position and nature of the alteration.

MLPA and MS-MLPA. We used a commercial MLPA kit for NF2 gene analysis (SALSA P044 NF2) and a kit for the methylation status of the promoter region of 25 cancerrelated genes (SALSA MS-MLPA Kit ME001; MRC-Holland, Amsterdam, The Netherlands). Information regarding the probe sequences and ligation sites can be found at http://www. mlpa.com. The MLPA protocol was performed as described by the manufacturers, using $100 \mathrm{ng}$ of DNA from control and tumor samples. Data analysis was performed with MRCCoffalyser software (MRC-Holland).

Expression arrays. For the gene expression analysis by microarray membranes we used the GEArray ${ }^{\mathrm{TM}} \mathrm{Q}$ Series HS-006 (SuperArray, Bethesda, MD) containing 96 cDNA fragments in quadruplicate, as well as housekeeping genes and negative controls. The manufacturer's protocol was used. The cDNA was obtained from $200 \mathrm{ng}$ of mRNA by reverse transcription. Labeling with $\left[{ }^{33} \mathrm{P}\right] \mathrm{dCTP}$ was performed using linear amplification (AmpoLabeling-LPR.SuperArray). Labeled probes were hybridized in the membranes at $60^{\circ} \mathrm{C}$ for $24 \mathrm{~h}$. Membranes were exposed to screen storage (Cyclone Storage Phosphor Screen), and images were obtained with the Cyclone 3000 and analyzed by the Phoretix ${ }^{\mathrm{TM}}$ Array software (Nonlinear Dynamics Ltd.).

$Q-P C R$. To validate the microarray data obtained, an assay was conducted using the ABI PRISM 7900HT Sequence Detection System, which allows for the relative quantification of nucleic acids through the comparative $\mathrm{C}_{\mathrm{T}}$ method. GAPDH was used as an endogenous control gene. Expression levels of 4 TaqMan ${ }^{\circledR}$ probes (Applied Biosystems) were measured (selected by its various expressions from the 96 genes included in the microarray: BCL2L1, FOS, MDM 2 and TIMP1). The fluorescence data were analyzed with the SDS software to obtain the values of relative expression. To check consistency and correlation of data obtained from the expression by microarray compared with the corresponding data obtained by Q-PCR an intra-class correlation analysis was performed.

Statistical analysis. Analyses were performed using BRBArrayTools 3.5.0 Patch_1 by Dr Richard Simon and Amy Peng Lam. Sample data were normalized by using $G A P D H$, RPL13A and ACTB genes. Genes whose expression differed by at least 1.5 -fold from the median in at least $20 \%$ of the arrays were retained. Cluster analysis: we used hierarchical clustering to cluster the samples and used R (reproducibility) and $\mathrm{D}$ (discrepancy) measures to evaluate the robustness of the clusters. Class comparison: we identified genes differentially expressed among the two classes using a random-variance t-test (F-test for more than 2 classes). Genes were considered statistically significant at $p<0.001$. We also 
performed a global test of whether the expression profiles differed between the classes by permuting the labels of which arrays corresponded to which classes. SAM (significative analysis of microarrays): we also identified genes that were differentially expressed among the two classes by using a multivariate permutation test to provide $90 \%$ confidence that the false discovery rate (FDR) was less than $10 \%$. The test statistics used are random variance t-statistics for each gene. Class prediction: we developed models for utilizing gene expression profile to predict the class of future samples based on the compound covariate predictor, diagonal linear discriminant analysis, nearest neighbor classification, and support vector machines with linear kernel. The models incorporated genes that were differentially expressed among genes at $\mathrm{p}<0.005$ as assessed by the random variance t-test. We estimated the prediction error of each model using leave-one-out cross-validation (LOOCV). 1000 random permutations were used. All array experiment information and data has been loaded into ArrayExpress (www.ebi.ac.uk/ arrayexpress).

\section{Results}

We analyzed 65 frozen samples, corresponding to 42 meningiomas and 23 schwannomas. Using 5 microsatellites markers, LOH for $22 \mathrm{q}$ was detected in $53.6 \%$ of GI meningiomas, $83.3 \%$ of GII meningiomas, $100.0 \%$ of recurrent meningiomas, as well as $30.4 \%$ of the schwannomas (Table I). Except for M41 and S23, all samples with LOH showed loss of the 5 analyzed markers. NF2 gene mutations were identified by PCR/dHPLC and sequencing in 26/65 (40\%) of the samples. Meningiomas showed small deletions in $4 / 42(9.5 \%)$, small insertions in $3 / 42(7.1 \%)$, nonsense mutations in $4 / 42(9.5 \%)$, splicing mutations in $4 / 42(9.5 \%)$ and intronic changes in $3 / 42(7.1 \%)$, accounting for $42.9 \%$ $(18 / 42)$ of the meningiomas. Schwannomas showed small deletions in $2 / 23(8.7 \%)$, nonsense mutations in $2 / 23(8.7 \%)$, splicing mutations in $2 / 23(8.7 \%)$ and intronic changes in $2 / 23(8.7 \%)$, accounting for $34.8 \%$ (8/23) of the schwannomas. Only the nonsense mutation g.592C $>$ T-arg 57 stop (S16) has been previously reported (33). Intronic mutation IVS4+47delA was found in 2 meningioma samples (M16 and M17) and 1 schwannoma sample (S8), and splicing mutation IVS8+2T $>\mathrm{G}$ was found in 3 meningioma samples (M14, M15 and M24) and 1 schwannoma sample (S11) as well as in their corresponding DNA samples, except for 1 meningioma (Table I).

Multiplex ligation-dependent probe amplification (MLPA) analyses showed complete NF2 gene loss in 34/65 $(52.3 \%)$ of the samples, including two samples with partial losses on the other allele. NF2 gene partial losses also were found in 4/65 (6.15\%). MLPA also showed duplications on $1 \mathrm{p} 36(20 \%), 8 \mathrm{q} 24(10.8 \%), 9 \mathrm{q}(16.9 \%), 10 \mathrm{q}(15.4 \%), 12 \mathrm{q}$ $(33.9 \%)$ and $17 \mathrm{q}(4.6 \%)$, and deletions on $1 \mathrm{p} 36(15.4 \%)$, 6q25-q27 (21.5\%) and 14q (24.6\%) (Table I). MethylationSpecific MLPA (MS-MLPA) analysis showed alterations in 10 meningiomas and 2 schwannomas. Hypermethylation was found for genes $C D K N 2 B$ and $R A S S F 1$ in 4 samples each and for CDH13, IGSF4, CASP8, CDKN1B, PTEN and CHFR genes in 1 sample each. $C A S P 8$ and $C D K N 1 B$ genes, studied both in MS-MLPA and microarray, showed low expression in the two samples with promoter hypermethylation.

Microarray expression analysis for 96 cancer-related genes was performed in 23 schwannomas, 42 meningiomas and 3 normal cerebral meninges as controls. No normal Schwann cell controls were available. Microarray data were validated by Q-PCR, and intra-class correlation analysis of the expression levels of BCL2L1, FOS, MDM2 and TIMP1 genes was performed to check consistency and correlation of data obtained. Data acquired in our tumor series clearly identified, by unsupervised hierarchical cluster analysis, two main groups of tumors (I and II) and three groups of genes (A, B and C) (Fig. 1). As a global analysis this statistical method found one group of samples, differentiating between meningiomas (I3) and schwannomas (I2), with expression patterns similar to normal cerebral meninges (I1), and another group of samples, also differentiating between meningiomas (II5) and schwannomas (II4), with expression patterns different from the normal cerebral meninges. Differences in gene expression for groups $\mathrm{A}$ and $\mathrm{B}$ are responsible for the two main molecular groups of samples, in the same way that genes in group $\mathrm{C}$ distinguish each of the two tumor types, schwannomas and meningiomas within each of these two main sample groups.

For class comparison, differentially expressed genes [p $<0.001$ and SAM (significative analysis of microarrays)] among classes were identified. Comparison between normal cerebral meninges and meningiomas showed 7 differentially expressed genes: FOS, ICAM1, PLAUR, IL8, FLT1, $S E R P I N E 1$ and $C D K N 1 A$. Class comparison including only the 35 meningioma samples in subgroups I3 and II5 found 38 differentially expressed genes (Table II). Analyzing meningiomas by tumor grade and recurrence, the S100A4 gene was differentially expressed, increasing its expression in samples GII as compared to GI and also in the recurrent meningiomas with respect to GII. SAM analysis also showed 2 genes with decreased expression in samples GII with respect to GI samples: IFNAI and MMP9 (Table II).

Comparative expression patterns between meningiomas and schwannomas showed 16 genes with lower expression and 3 genes with higher expression in meningiomas with respect to schwannomas. As performed with meningiomas, we achieved a class comparison including only the schwannoma samples in subgroups I 2 and II4, and we identified 20 differentially expressed genes (Table II).

Class comparison in meningiomas and schwannomas, classifying them by presence or absence of $\mathrm{LOH}$ for $22 \mathrm{q}$ and for NF2 gene alteration detected by MLPA, showed 15 genes with lower expression in those samples with $\mathrm{LOH}$ and 11 genes with lower expression in those samples with NF2 gene alteration detected by MLPA (Table II). When the comparison was performed classifying samples by presence or absence of any NF2 gene alteration ( $\mathrm{LOH}$, MLPA or mutational analysis), we found 3 genes differentially expressed (PLAUR, CDKN1A and FLT1), with lower expression in the altered samples (Table II). We did not identify gene ontology (GO) groups of genes whose expressions were differentially regulated among the classes. There were no genes with expression levels significantly related to patient age or gender. 


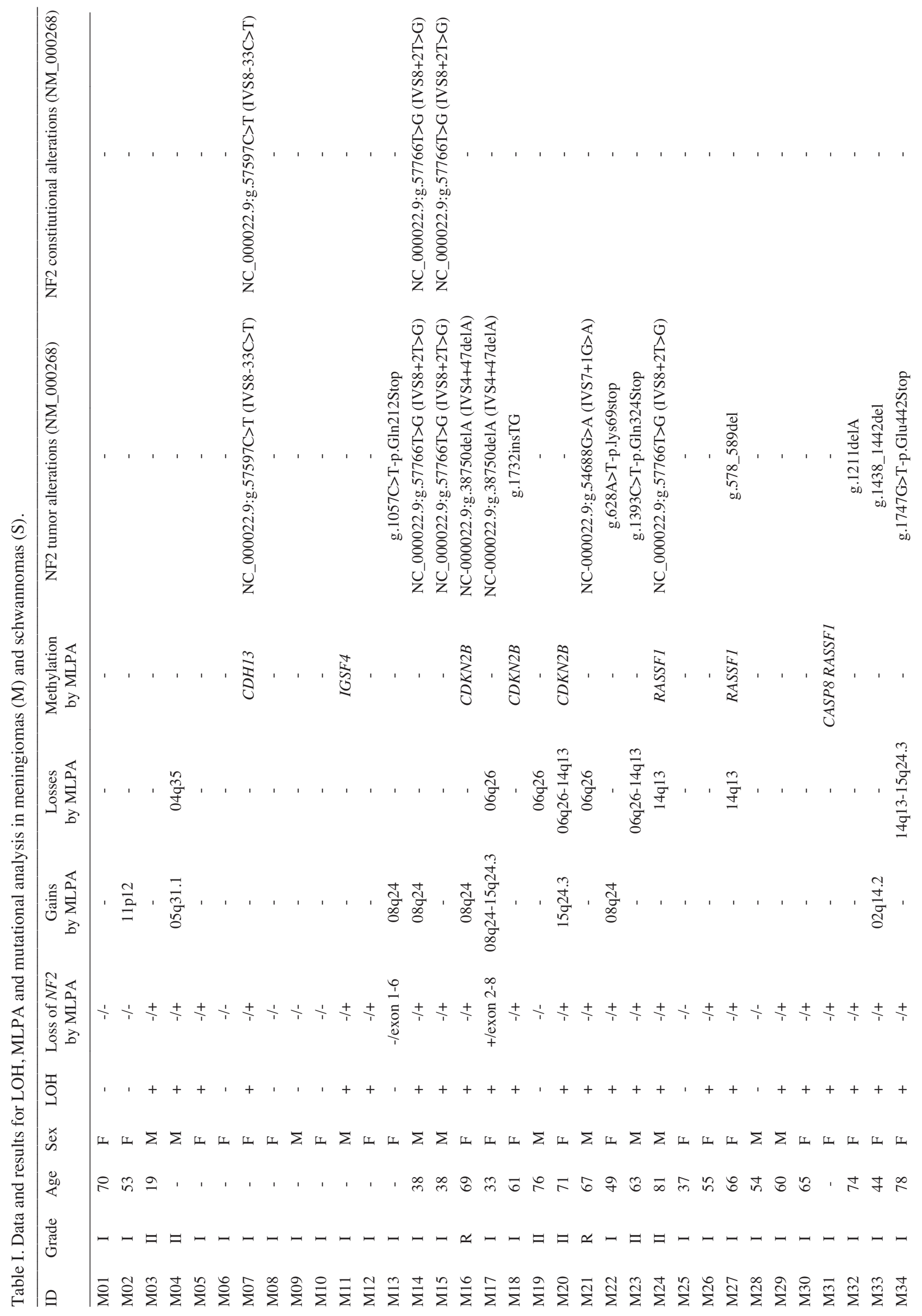




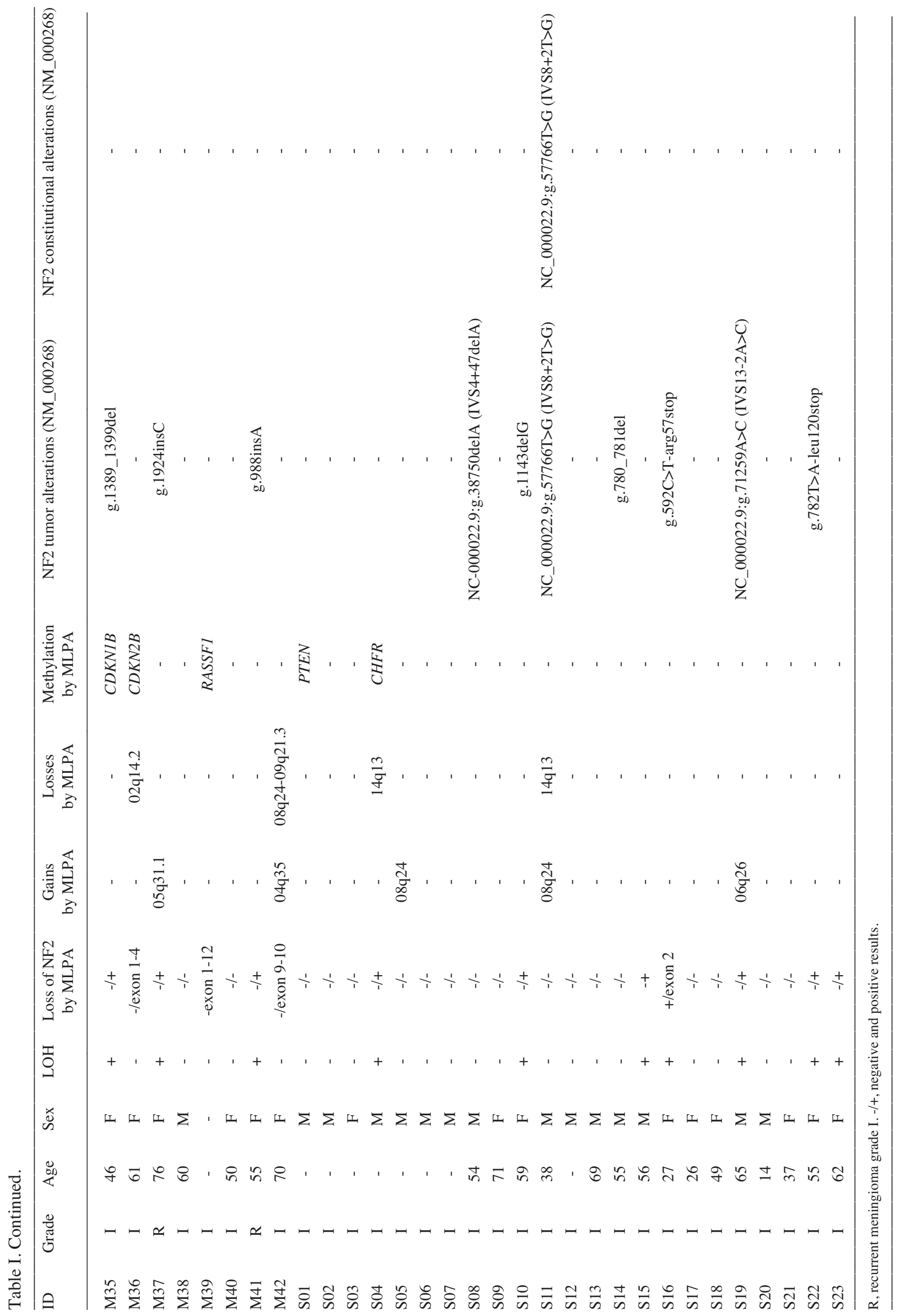




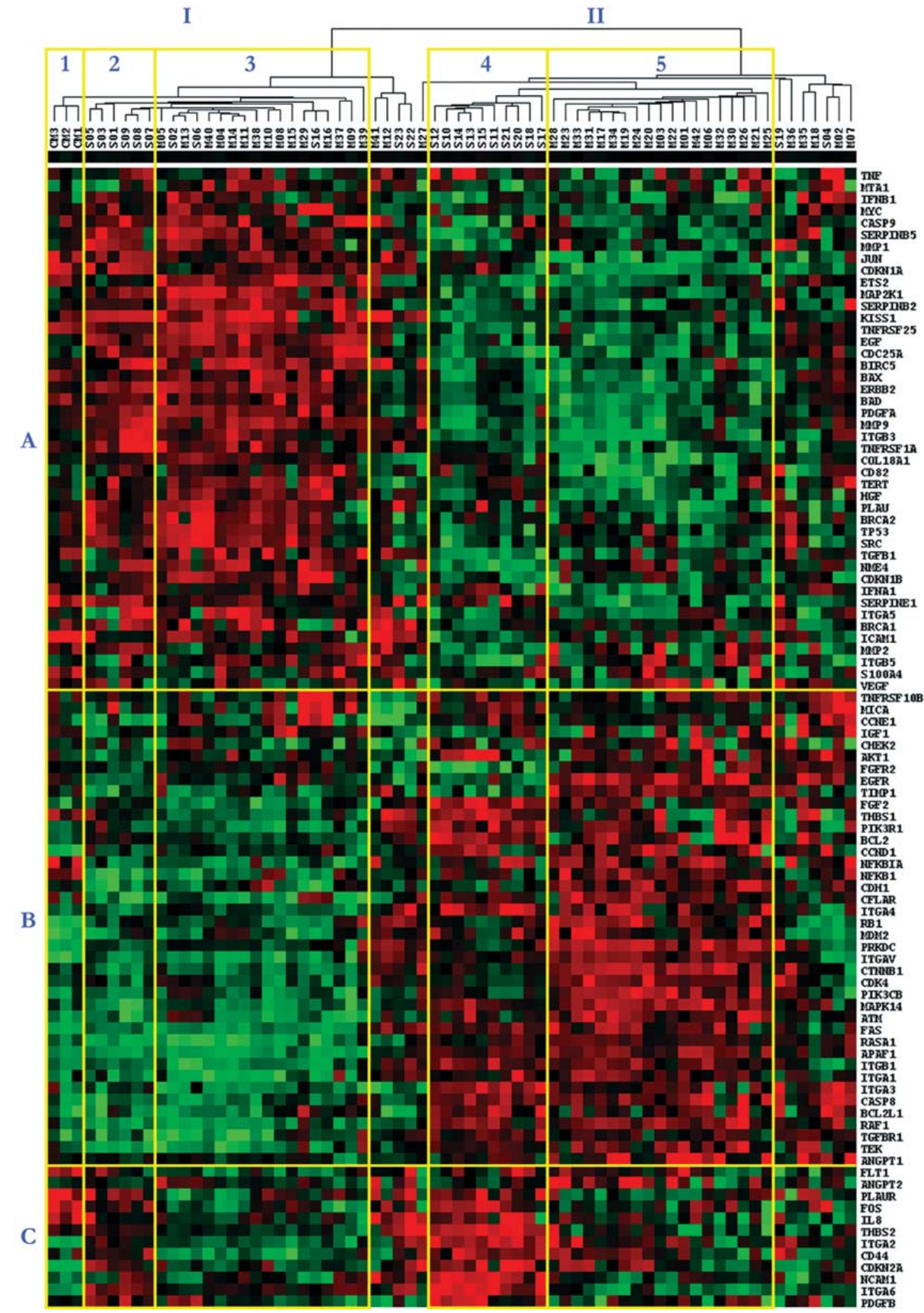

Figure 1. Sorting by unsupervised hierarchical cluster the expressions of 96 cancer-related genes in 3 normal cerebral meninges (CM), 42 meningiomas (M) and 23 schwannomas (S). Analysis identified two main groups of tumors (I and II) and three groups of genes (A, B and C), differentiating between meningiomas (I3 and II5) and schwannomas (I2 and II4) with expression patterns similar to or different to from the normal cerebral meninges (I1). Genes in groups A and B established the two main groups of samples, in which schwannomas and meningiomas can be distinguished by the genes included in group C. Red denotes higher relative expression, and green denotes lower relative expression levels.

\section{Discussion}

The mutational study of the NF2 gene found similar percentages as those already described (Human Gene Mutation
Database; www.hgmd.cf.ac.uk), both in total and by type of mutation. The splicing mutation IVS $8 \mathrm{~T}+2>\mathrm{G}$ was detected in 3 meningiomas and 1 schwannoma (15.38\%), as well as in the peripheral blood DNA from 3 of them, suggesting 
Table II. Class comparison and SAM analysis showing the mean of the expression intensities and the ratio for the different classes.

\begin{tabular}{|c|c|c|c|c|c|c|c|}
\hline \multirow{2}{*}{\multicolumn{4}{|c|}{ different classes. }} & \\
\hline & & & & Gene & CM:I3 & CM:II5 & I3:II5 \\
\hline Gene & Ratio M:CM & \multicolumn{2}{|c|}{ p-value/SAM } & \multicolumn{4}{|l|}{ Meningioma subgroups } \\
\hline \multirow{2}{*}{\multicolumn{4}{|c|}{$\begin{array}{l}\text { Meningioma/cerebral } \\
\text { meninges }\end{array}$}} & & & & \\
\hline & & & & $P D G F A$ & -1.6 & 3.9 & 6.2 \\
\hline \multirow{2}{*}{ CDKN1A } & \multirow{2}{*}{-5.9} & \multirow{2}{*}{\multicolumn{2}{|c|}{ SAM1 }} & PIK $3 C B$ & 1.0 & -3.0 & -3.0 \\
\hline & & \multirow{2}{*}{\multicolumn{2}{|c|}{ SAM1 }} & $P L A U$ & 0.9 & 4.3 & 4.9 \\
\hline FLT1 & -7.8 & & & $P R K D C$ & -2.1 & -7.8 & -3.7 \\
\hline FOS & -24.6 & \multicolumn{2}{|r|}{$\mathrm{p}<0.001$} & $R A F 1$ & 2.1 & -3.1 & -6.5 \\
\hline ICAMI & -6.9 & \multicolumn{2}{|r|}{$\mathrm{p}<0.001$} & RASAl & 3.2 & -5.4 & -17.4 \\
\hline IL8 & -12.2 & \multicolumn{2}{|r|}{$\mathrm{p}<0.001$} & SERPINB2 & -1.7 & 2.6 & 4.4 \\
\hline PLAUR & -10.7 & & $\mathrm{p}<0.001$ & SERPINE1 & 2.7 & 14.0 & 5.1 \\
\hline SERPINE1 & -6.6 & & SAM1 & $T I M P 1$ & 1.9 & -1.7 & -3.2 \\
\hline Gene & Ratio I:II & & SAM & TNFRSF 25 & 1.5 & 6.7 & 4.5 \\
\hline Grade I and II - meningiomas & & & & FAS & 0.9 & -6.3 & $\begin{array}{r}3.8 \\
-5.7\end{array}$ \\
\hline IFNAI & 5.8 & & SAM2 & & & & \\
\hline$M M P 9$ & 5.8 & & SAM2 & Gene & Ratio M:S & $\mathrm{p}-\mathrm{v}$ & value/SAM \\
\hline Gene & GI:GII & GI:R & GII:R & Meningioma/schwannoma & & & \\
\hline Grade and R - meningiomas & & & & $\begin{array}{l}C D 44 \\
C D K N 1 A\end{array}$ & $\begin{array}{l}-2.6 \\
-2.0\end{array}$ & & $\begin{array}{l}\mathrm{p}<0.001 \\
\text { SAM3 }\end{array}$ \\
\hline S100A4 & -2.4 & -3.7 & -1.5 & $C D K N 2 A$ & -3.9 & & $\mathrm{p}<0.001$ \\
\hline Gene & CM:I3 & CM:II5 & I3:II5 & COL18A1 & -2.0 & & SAM3 \\
\hline Meningioma subgroups & & & & $\begin{array}{l}E G F R \\
E G F R ?\end{array}$ & 4.1 & & $\begin{array}{l}\mathrm{p}<0.001 \\
\mathrm{p}<0.001\end{array}$ \\
\hline I3 and II5 & & & & $\begin{array}{l}\text { FGFR2 } \\
\text { FOS }\end{array}$ & $\begin{array}{r}2.3 \\
-3.9\end{array}$ & & $\begin{array}{l}\mathrm{p}<0.001 \\
\mathrm{p}<0.001\end{array}$ \\
\hline$A P A F 1$ & 1.7 & -11.4 & -19.7 & IL8 & -3.5 & & $\mathrm{p}<0.001$ \\
\hline ATM & 1.1 & -2.9 & -3.1 & ITGA2 & -3.3 & & $\mathrm{p}<0.001$ \\
\hline$B A D$ & 1.2 & 7.7 & 6.6 & ITGA3 & -3.4 & & $\mathrm{p}<0.001$ \\
\hline$B A X$ & 1.1 & 7.5 & 7.0 & ITGA6 & -4.3 & & $\mathrm{p}<0.001$ \\
\hline BIRC5 & -1.9 & 6.5 & 12.2 & NCAMI & -2.9 & & $\mathrm{p}<0.001$ \\
\hline CASP9 & 0.8 & 2.4 & 3.1 & $P D G F B$ & -2.0 & & SAM3 \\
\hline$C D C 25 A$ & -2.2 & 2.3 & 5.0 & $P L A U$ & -2.2 & & SAM3 \\
\hline$C D K N 1 A$ & 2.1 & 12.6 & 6.1 & PLAUR & -2.9 & & $\mathrm{p}<0.001$ \\
\hline COLI8Al & 0.9 & 5.1 & 5.6 & SERPINE1 & -3.1 & & $\mathrm{p}<0.001$ \\
\hline CTNNB1 & 2.5 & -4.9 & -12.3 & THBS1 & -2.6 & & SAM3 \\
\hline$E G F$ & -2.4 & 2.5 & 6.1 & THBS2 & -4.7 & & $\mathrm{p}<0.001$ \\
\hline$E R B B 2$ & -1.7 & 5.3 & 9.2 & TIMP1 & 3.0 & & $\mathrm{p}<0.001$ \\
\hline ETS2 & 0.9 & 3.7 & 4.3 & & & & \\
\hline$H G F$ & -1.6 & 2.7 & 4.3 & Gene & Ratio +:- & $\mathrm{p}-\mathrm{v}$ & value/SAM \\
\hline ICAMI & 4.7 & 8.7 & 1.9 & LOH meningiomas & & & \\
\hline IFNAI & 1.3 & 8.5 & 6.5 & and schwannomas & & & \\
\hline ITGAI & 2.5 & -3.3 & -8.3 & CDKNIA & -2.3 & & SAM4 \\
\hline ITGA6 & -2.6 & 1.6 & 4.2 & CHEK2 & -2.0 & & $\mathrm{p}<0.001$ \\
\hline$I T G A V$ & -2.2 & -36.3 & -16.3 & COL18A1 & -2.4 & & $\mathrm{p}<0.001$ \\
\hline$I T G B 1$ & 1.5 & -3.5 & -5.2 & $E R B B 2$ & -2.3 & & SAM4 \\
\hline$I T G B 3$ & -1.6 & 3.9 & 6.3 & $F L T 1$ & -2.9 & & $\mathrm{p}<0.001$ \\
\hline$J U N$ & 2.1 & 6.7 & 3.2 & FOS & -2.7 & & SAM4 \\
\hline KISS1 & -2.1 & 6.1 & 12.8 & ITGA2 & -2.0 & & SAM4 \\
\hline$M A P 2 K 1$ & -1.6 & 1.9 & 3.1 & ITGA6 & -2.4 & & SAM4 \\
\hline MAPK14 & 1.8 & -3.3 & -6.0 & ITGB3 & -2.2 & & SAM4 \\
\hline$M M P 9$ & -2.1 & 6.7 & 14.0 & $M M P 9$ & -2.1 & & SAM4 \\
\hline
\end{tabular}

Table II. Continued. 
Table II. Continued.

\begin{tabular}{|c|c|c|}
\hline Gene & Ratio +:- & p-value/SAM \\
\hline \multicolumn{3}{|c|}{$\begin{array}{l}\text { LOH meningiomas } \\
\text { and schwannomas }\end{array}$} \\
\hline NCAMI & -2.2 & SAM4 \\
\hline PLAUR & -2.1 & $\mathrm{p}<0.001$ \\
\hline SERPINE1 & -2.2 & SAM4 \\
\hline THBS2 & -2.0 & SAM4 \\
\hline$T N F$ & -2.2 & SAM4 \\
\hline \multicolumn{3}{|c|}{$\begin{array}{l}\text { MLPA meningiomas } \\
\text { and schwannomas }\end{array}$} \\
\hline$C D K N 1 A$ & -2.4 & SAM5 \\
\hline COL18A1 & -2.3 & SAM5 \\
\hline FLT1 & -2.7 & $\mathrm{p}<0.001$ \\
\hline FOS & -2.6 & SAM5 \\
\hline ITGA3 & -2.3 & SAM5 \\
\hline ITGA6 & -2.6 & SAM5 \\
\hline NCAMI & -2.3 & SAM5 \\
\hline PLAUR & -2.9 & $\mathrm{p}<0.001$ \\
\hline SERPINE1 & -2.2 & SAM5 \\
\hline$T H B S 2$ & -2.6 & SAM5 \\
\hline$T N F$ & -2.2 & SAM5 \\
\hline \multicolumn{3}{|c|}{$\begin{array}{l}\text { NF2 meningiomas } \\
\text { and schwannomas }\end{array}$} \\
\hline CDKNIA & -2.3 & SAM6 \\
\hline FLT1 & -2.6 & SAM6 \\
\hline PLAUR & -2.8 & $\mathrm{p}<0.001$ \\
\hline Gene & Ratio I2:II4 & $\mathrm{p}$-value \\
\hline
\end{tabular}

Schwannoma subgroups

I 2 and II4

$\begin{array}{lrl}\text { APAF1 } & -19.6 & \mathrm{p}<0.001 \\ \text { CASP8 } & -6.6 & \mathrm{p}<0.001 \\ \text { CFLAR } & -4.1 & \mathrm{p}<0.001 \\ \text { ERBB2 } & 3.5 & \mathrm{p}<0.001 \\ \text { FAS } & -7.9 & \mathrm{p}<0.001 \\ \text { FGF2 } & -5.2 & \mathrm{p}<0.001 \\ \text { ITGA2 } & -7.6 & \mathrm{p}<0.001 \\ \text { ITGA3 } & -14.3 & \mathrm{p}<0.001 \\ \text { ITGA4 } & -8.2 & \mathrm{p}<0.001 \\ \text { ITGAV } & 7.6 & \mathrm{p}<0.001 \\ \text { ITGB1 } & -8.1 & \mathrm{p}<0.001 \\ \text { TGB3 } & 4.7 & \mathrm{p}<0.001 \\ \text { KISS1 } & 11.4 & \mathrm{p}<0.001 \\ \text { MAPK14 } & -7.2 & \mathrm{p}<0.001 \\ \text { MMP2 } & 3.7 & \mathrm{p}<0.001 \\ \text { MMP9 } & 6.1 & \mathrm{p}<0.001 \\ \text { RASA1 } & -20.8 & \mathrm{p}<0.001 \\ \text { ITEK } & -13.7 & \mathrm{p}<0.001 \\ \text { TGFB1 } & 2.1 & \mathrm{p}<0.001 \\ \text { THBS2 } & -6.3 & \mathrm{p}<0.001 \\ & & \end{array}$

Table II. Continued.

The p-value/SAM columns show genes found statistically significant at $\mathrm{p}<0.0001$ or by SAM. With 90 th percentile confidence, the false discovery rate among significant genes is: SAM1 $=0.09804$, SAM $2=0$, SAM $3=0.08019$, SAM4 $=0.08654$, SAM $5=0.07059$, SAM6 $=0 . C M$, normal cerebral meninges; R, recurrent meningiomas grades I; I2, I3, II4, II5, subgroups as detailed in Fig. 1; +/-, negative and positive results as detailed in Table I.

a prevalent mutation in our population. In agreement with previous data $(3,4,9,12,34)$, through the $22 \mathrm{q} \mathrm{LOH}$ analysis, we detected alterations in $30.4 \%$ of the schwannomas and $64.3 \%$ of the meningiomas, and a significant increase in this alteration paralleled the increase of aggressiveness in meningioma samples $(53.6 \%$ in GI, $83.3 \%$ in GII and $100.0 \%$ of the recurrent meningiomas).

MLPA analysis in meningiomas and schwannomas confirmed the loss of one complete $N F 2$ allele in all samples with a positive result for $22 \mathrm{q} \mathrm{LOH}$. We also found partial losses of the NF2 gene in 2 samples with $22 \mathrm{q} \mathrm{LOH}$ and 4 samples without 22q LOH. The MLPA technique contributes to an accurate identification of alterations that cannot be detected by conventional techniques, and has been used previously in two different studies to search for alterations in the NF2 gene in sporadic and familiar meningiomas, finding $6 \%$ and $48 \%$ of cases with complete deletions and $18 \%$ and $26 \%$ of cases, respectively, with partial deletions $(35,36)$.

MLPA analysis showed that gains and losses in regions other than $22 q$ are frequent in GI meningiomas and that their frequency increases with tumoral grade. Atypical and anaplastic meningiomas frequently show loss of $1 \mathrm{p}(76 \%)$, $14 q(43 \%)$ and $6 \mathrm{q}(33 \%)$, and gains in $9 \mathrm{q}(33 \%), 12 \mathrm{q}(43 \%)$ and $17 q 21(33 \%)$, usually accompanied by $22 \mathrm{q} \mathrm{LOH}(8,9,34)$. Our results showed frequent losses of 1 p36 (15.4\%), 14q $(24.6 \%)$ and $6 \mathrm{q}(21.5 \%)$, and duplications in $9 \mathrm{q} 34(16.9 \%)$, $12 \mathrm{q} 24(33.9 \%)$ and $17 \mathrm{q} 21(4.6 \%)$, suggesting the presence of possible TSGs in these regions. The decreased percentages obtained in our study can be explained by the composition of the series studied, comprised mainly of GI meningiomas.

Additionally, we found duplications in $8 \mathrm{q}$ in $5 / 42$ (10.8\%) of the meningiomas and $2 / 23$ of the schwannomas. This is the first report of frequent $8 \mathrm{q}$ duplications, since the only report available refers to a highly aberrant karyotype in a recurrent malignant meningioma (37). The specific MLPA probe that hybridizes in PTEN promoter, a gene virtually excluded in schwannomas and meningiomas $(38,39)$, detected duplications of $10 \mathrm{q}(15.4 \%)$. If this represents a duplication of PTEN or a gain of 10q, it would be the first description of this alteration, contrary to its usual loss. We cannot discard the possibility that this region could contain other TSGs.

As previously described, we found aberrant promoter hypermethylation in schwannomas and meningiomas for the CDKN2B $(6.15 \%)$ and RASSF $1(6.15 \%)$ genes $(7,40)$. The silencing of $C D K N 2 B(9 \mathrm{p} 21)$, a cyclin-dependent kinase inhibitor (41), and RASSF1 (3p21.3), involved in DNA repair and inhibition of the accumulation of cyclin D1 (42), as well 
as the presence of another 6 genes (CDH13, IGSF4, CASP8, $C D K N 1 B, P T E N$ and $C H F R$ ) that also showed promoter hypermethylation in one sample each, corroborates previous studies describing that this mechanism could contribute as a viable alternative to the traditional form of deletion plus mutation in the tumorigenesis of these neoplasms $(6,16,18)$.

Taken as a whole, the cluster analysis identified two main groups of tumors (I and II) and three groups of genes (A, B and $\mathrm{C}$ ), allowing for discrimination between meningiomas and schwannomas within each group (Fig. 1). In the subsequent analysis, the gene expression levels comparison between normal cerebral meninges and meningiomas showed 7 differentially expressed genes: FOS, ICAM1, PLAUR, IL8, FLT1, SERPINE1 and CDKN1A. In meningioma samples we found low expression of FOS (24.6-fold), a known TSG that encodes a nuclear protein involved in signal transduction. Down-regulation of FOS might be an important event in the tumorigenesis of meningiomas. ICAM-1 (19p13) shows variable expression levels in different cancer types (43). Since the over-expression of this gene is important in senescence (44), its negative regulation (6.9-fold in our series) could prevent the inhibition of proliferation in cells with a proinflammatory phenotype in meningiomas. Silencing of PLAUR (19q13) in meningioma cells inhibits tumor growth and invasion (45). However, the reduced expression of PLAUR in our series (10.7-fold) correlates with reported PLAUR decreased immunoreactivity in some regions of GII meningiomas (46). SERPINE1 (7q21.3-q22) enhances or inhibits tumor growth due to an expression-dependent regulation of angiogenesis (47). As described for prostate cell carcinoma (48), in our tumor series we found reduced SERPINE1 expression (6.6-fold). A high percentage of meningiomas express chemokine receptors, but have low patterns of IL8 (4q13-q21) expression in the same samples $(46,49)$. These data are consistent with our findings in which meningiomas expressed a lesser amount of IL8 (12.2-fold) compared to controls. FLT1 (13q12), a VEGF receptor, seems to be a negative regulator of endothelial cell proliferation, and has high affinity for $V E G F$ in addition to a low tyrosine kinase activity (50). The low expression of FLT1 in our series (7.8-fold) could allow the union of other VEGF receptors with increased activity, thus promoting vascular proliferation in meningiomas. Finally, decreased expression of the cell cycle regulator $C D K N 1 A(6 \mathrm{p} 21.2)$ has been described in a large number of meningiomas (51). The results obtained in our series also showed a decreased expression of this gene in meningiomas (5.9-fold), preventing its oncosuppressor activity.

The comparison analysis between meningioma subgroups I3 and II5 showed 38 differentially expressed genes between both subgroups, allowing the establishment of a molecular signature for each one. While we cannot say that these groups are related to tumor grade in a statistically significant way because of the small number of GII meningiomas studied, we can suggest that there is a clear trend toward grouping GII samples in group II5, whose global expressions are different from the controls (Fig. 1). This II5 meningioma tumors group includes IFNAI and MMP9, which were differentially expressed between meningiomas GI and GII when analyzed in the entire pool of meningiomas. IFNAI (9p22) induces apoptosis associated with caspases, $P I 3 K$ and $B A X$ and induces the expression of PLAUR $(52,53)$. Therefore, the lower IFNAI expression in GII meningiomas (5.8-fold) promotes the inhibition of apoptosis in these atypical meningiomas and is not favorable to the expression of PLAUR which, as noted above, is a constant found in the whole pool of meningiomas when compared to controls. On the other hand, MMP9 (20q11.2-q13.1) is involved in degradation of the extracellular matrix and its over-expression is associated with the invasive potential of meningiomas (54). Furthermore, the matrix metalloproteinases (MMPs) inhibitor TIMP1 showed increased expression and PLAU showed decreased expression in meningiomas group II5 compared with group I3. The higher expression of MMP9 in both GI meningiomas and the I3 group, compared with GII meningiomas and the II5 group, respectively, could therefore promote tumor progression (55). Additionally, S100A4, involved in the regulation of cell differentiation and progression, is expressed to a lesser extent in GI meningiomas and to a greater extent in GII, and to an even greater extent in GI recurrent meningiomas; accordingly, the increased S100A4 expression could enhance the invasive phenotype in this neoplasm. Increased expression of $S 100 A 4$, located at 1q, is consistent with the frequent gains in this region in atypical and anaplastic meningiomas $(2,34)$ and therefore could be a candidate in tumor progression for meningiomas.

Using gene expression microarrays in a previous study, all studied GI meningiomas were found to fall into a so-called 'low-proliferative group', all GIII meningiomas fall into a 'high-proliferative group' and GII meningiomas fall into one of these groups (56). Twenty-eight genes were differentially expressed by SAM between GI and GII meningiomas and 1212 genes were differentially expressed between GI and GIII meningiomas ( $\mathrm{p}<0.05$ and fold $>2$ ). Although our series do not include GIII meningiomas, our series showed 38 differentially expressed genes at $\mathrm{p}<0.001$ and established a well defined molecular subgroup classification for GI and GII meningiomas. The results reported by Carvalho et al support our work and confirm the presence of molecular subgroups in meningiomas (56).

As with meningiomas, schwannomas showed two distinct groups in the cluster analysis (I2 and II4). The comparison between these two subgroups of samples revealed 20 differentially expressed genes, half of which were found differentially expressed between the two subgroups of meningiomas and showing similar variations (Table II). A previous work identified 14 genes including MMPs, growth factors and receptors and tyrosine kinases with increased or decreased mRNA levels in schwannoma compared with normal Schwann cells $(25,34)$. The lack of appropriate Schwann cell controls in our study does not allow the establishment of differences in gene expression between normal and tumoral cells. However, the comparison between meningiomas and schwannomas permits the establishment of differential expression patterns between two types of tumors that share main characteristics: the alterations in the NF2 gene and the coexistence of neurofibromatosis type II. Our findings showed 16 genes with lower expression and 3 genes with higher expression in meningiomas compared to schwannomas. CDKN1A, FOS, IL8, PLAUR and SERPINE1 
genes expressed 2- to 4-fold less in meningiomas than in schwannomas. However, these genes expressed 6- to 25-fold less in meningioma than in normal controls. EGFR, FGFR2 and TIMPI showed higher expression (2- to 4-fold) in meningiomas than schwannomas. These genes showed no differences between controls and meningiomas, but they were expressed more in subgroup II5 of meningiomas. A low immunoreactivity of EGFR (7p12) has been associated with poor prognosis in atypical meningiomas (57), and alteration of EGFR in NF2-associated tumors has been found in schwannoma rat cell lines (58). Accordingly, assessment of the EGFR expression levels in these tumors may be useful for a therapeutic approach. The FGFR2 gene (10q26) participates in processes such as cell proliferation, migration and differentiation, so this tyrosin kinase receptor is also a potential therapeutic target in many tumor types, especially those of neuronal, epithelial and skeletal origin (59).

We also analyzed expression patterns in search of possible differences between tumors with or without $22 \mathrm{q}$ or $N F 2$ abnormalities. The class comparison analysis showed a group of 15 genes with significantly lower expression in meningioma and schwannoma samples with $22 \mathrm{q} \mathrm{LOH}$ and a group of 11 genes with significantly lower expression in samples with NF2 gene alteration identified by MLPA (Table II). In the latter group, only the ITGA3 gene is not present in both groups (MLPA and LOH). The decreased expression of these genes could be a direct or indirect result of the absence or decreased expression of the $N F 2$ gene, especially for CDKN1A, FLT1 and PLAUR, since they were also found differentially expressed when the comparison was conducted by the presence or absence of any alteration in the NF2 gene (chromosomal loss, deletion or mutation).

From the 5 genes present in the $22 \mathrm{q}$ LOH group but not in the MLPA group, CHEK2 also located at 22q, displayed half expression; this can be explained by the loss of one of its alleles $(\mathrm{LOH})$. The decreased expression of the other 4 genes (ERBB2, ITGA2, ITGB3 and MMP9) may be due to the loss of one or more regulatory genes located at $22 \mathrm{q}$. As changes in the NF2 gene alone do not explain all cases of schwannomas and meningiomas, suggesting the involvement of one or more TSG located on chromosome 22, the study of cellular pathways of $E R B B 2, I T G A 2, I T G B 3$ and $M M P 9$ could lead to the identification of candidate TSGs on 22q.

With the class comparison results between meningioma and normal cerebral meninges, we decided to search for a predictor to enable us to further classify tumor samples as belonging to one of the two classes, because the classification of tumors based on patterns of gene expression could also be used as a prognostic marker with regard to evolution, disease-free times and survival. Using the expression of 96 cancer-related genes and with an optimized error at $\mathrm{p}<0.005$, we propose a set of 7 genes (FOS, ICAM1, PLAUR, IL8, APR, FLT1 and SERPINE1) that compose the classifier. Once validated, this classifier, which is based on a small number of genes, might permit an accurate diagnosis in cases where the histopathology can not and could have implications for evolution and post-surgical monitoring of patients, especially for those cases with widespread invasion in which is important to check the extent of the resection.
In conclusion, we have established the expression patterns of 96 specific cancer-related genes using low density cDNA microarrays in a series of meningioma and schwannoma tumor samples. In addition to identifying biologically relevant genes in the genesis and progression of theses two tumor types characterized by the $N F 2$ gene alterations and that coexist in the NF2 syndrome, expression analyses provided a molecular tumor sub-classification as a basis for future studies to identify potential phenotypes and to improve current methods of classification, which may include invasive capacity, metastatic potential, tumor recurrence or resistance and sensitivity to specific therapies.

\section{Acknowledgements}

This study is dedicated to the loving memory of M. Josefa Bello, (June 18, 1957 - March 4, 2006). We are indebted to Carolina Peña Granero for her technical support. This research was supported by the following grant: Fondo de Investigaciones Sanitarias, Ministerio de Sanidad (05/0829).

\section{References}

1. Louis DN, Ohgaki H, Wiestler OD, Cavenee WK, Burger PC, Jouvet A, Scheithauer BW and Kleihues P: The 2007 WHO Classification of Tumours of the central nervous system. Acta Neuropathol (Berl) 114: 97-109, 2007

2. Rey JA, Bello MJ, de Campos JM, Kusak E and Moreno S: Chromosomal involvement secondary to -22 in human meningiomas. Cancer Genet Cytogenet 33: 275-290, 1988.

3. Louis DN, Scheithauer BW, Budka H, von Deimling A and Kepes JJ: Meningiomas. In: World Health Classification of Tumors: Pathology and Geentics of Tumors of the Nervous System. Kleihues P and Cavenee WK (eds). IARC Press, Lyon, pp176-184, 2000

4. Lomas J, Bello MJ, Arjona D, Alonso ME, Martinez-Glez V, Lopez-Marin I, Aminoso C, de Campos JM, Isla A, Vaquero J and Rey JA: Genetic and epigenetic alteration of the NF2 gene in sporadic meningiomas. Genes Chromosomes Cancer 42: 314-319, 2005.

5. Van Tilborg AA, Morolli B, Giphart-Gassler M, de Vries A, van Geenen DA, Lurkin I, Kros JM and Zwarthoff EC: Lack of genetic and epigenetic changes in meningiomas without NF2 loss. J Pathol 208: 564-573, 2006.

6. Bello MJ, Aminoso C, Lopez-Marin I, Arjona D, GonzalezGomez P, Alonso ME, Lomas J, de Campos JM, Kusak ME, Vaquero J, Isla A, Gutierrez M, Sarasa JL and Rey JA: DNA methylation of multiple promoter-associated $\mathrm{CpG}$ islands in meningiomas: relationship with the allelic status at $1 p$ and $22 q$. Acta Neuropathol (Berl) 108: 413-421, 2004.

7. Liu Y, Pang JC, Dong S, Mao B, Poon WS and Ng HK: Aberrant $\mathrm{CpG}$ island hypermethylation profile is associated with atypical and anaplastic meningiomas. Hum Pathol 36: 416-425, 2005.

8. Bello MJ, de Campos JM, Kusak ME, Vaquero J, Sarasa JL, Pestana A and Rey JA: Allelic loss at 1p is associated with tumor progression of meningiomas. Genes Chromosomes Cancer 9: 296-298, 1994.

9. Leone PE, Bello MJ, de Campos JM, Vaquero J, Sarasa JL, Pestana A and Rey JA: NF2 gene mutations and allelic status of $1 \mathrm{p}, 14 \mathrm{q}$ and $22 \mathrm{q}$ in sporadic meningiomas. Oncogene 18 : 2231-2239, 1999.

10. Perry A, Gutmann DH and Reifenberger G: Molecular pathogenesis of meningiomas. J Neurooncol 70: 183-202, 2004.

11. Neff BA, Wellin DB, Akhmametyeva E and Chang LS: The molecular biology of vestibular schwannomas: dissecting the pathogenic process at the molecular level. Otol Neurotol 27: 197-208, 2006.

12. Antinheimo J, Sallinen SL, Sallinen P, Haapasalo H, Helin H, Horelli-Kuitunen N, Wessman M, Sainio M, Jaaskelainen J and Carpen O: Genetic aberrations in sporadic and neurofibromatosis 2 (NF2)-associated schwannomas studied by comparative genomic hybridization (CGH). Acta Neurochir (Wien) 142: 1099-1104, 2000 
13. Bruder CE, Ichimura K, Tingb O, Hirakawa K, Komatsuzaki A, Tamura A, Yuasa Y, Collins VP and Dumanski JP: A group of schwannomas with interstitial deletions on $22 q$ located outside the NF2 locus shows no detectable mutations in the NF2 gene. Hum Genet 104: 418-424, 1999.

14. Leone PE, Bello MJ, Mendiola M, Kusak ME, de Campos JM, Vaquero J, Sarasa JL, Pestana A and Rey JA: Allelic status of $1 \mathrm{p}, 14 \mathrm{q}$, and $22 \mathrm{q}$ and NF2 gene mutations in sporadic schwannomas. Int J Mol Med 1: 889-892, 1998.

15. Warren C, James LA, Ramsden RT, Wallace A, Baser ME, Varley JM and Evans DG: Identification of recurrent regions of chromosome loss and gain in vestibular schwannomas using comparative genomic hybridisation. J Med Genet 40: 802-806, 2003.

16. Gonzalez-Gomez P, Bello MJ, Alonso ME, Lomas J, Arjona D, Campos JM, Vaquero J, Isla A, Lassaletta L, Gutierrez M, Sarasa JL and Rey JA: CpG island methylation in sporadic and neurofibromatis type 2-associated schwannomas. Clin Cancer Res 9: 5601-5606, 2003.

17. Kino T, Takeshima H, Nakao M, Nishi T, Yamamoto $\mathrm{K}$, Kimura T, Saito Y, Kochi M, Kuratsu J, Saya H and Ushio Y: Identification of the cis-acting region in the NF2 gene promoter as a potential target for mutation and methylationdependent silencing in schwannoma. Genes Cells 6: 441-454, 2001.

18. Bello MJ, Martinez-Glez V, Franco-Hernandez C, Pefla-Granero C, de Campos JM, Isla A, Lassaletta L, Vaquero J and Rey JA: DNA methylation pattern in 16 tumor-related genes in schwannomas. Cancer Genet Cytogenet 172: 84-86, 2007.

19. Lomas J, Bello MJ, Alonso ME, Gonzalez-Gomez P, Arjona D, Kusak ME, de Campos JM, Sarasa JL and Rey JA: Loss of chromosome 22 and absence of NF2 gene mutation in a case of multiple meningiomas. Hum Pathol 33: 375-378, 2002.

20. Kleihues P, Louis DN, Scheithauer BW, Rorke LB, Reifenberger G, Burger PC and Cavenee WK: The WHO classification of tumors of the nervous system. J Neuropathol Exp Neurol 61: 215-225, 2002

21. Michiels S, Koscielny S and Hill C: Prediction of cancer outcome with microarrays: a multiple random validation strategy. Lancet 365: 488-492, 2005

22. Rhodes DR, Yu J, Shanker K, Deshpande N, Varambally R, Ghosh D, Barrette T, Pandey A and Chinnaiyan AM: Largescale meta-analysis of cancer microarray data identifies common transcriptional profiles of neoplastic transformation and progression. Proc Natl Acad Sci USA 101: 9309-9314, 2004.

23. Wen PY and Drappatz J: Novel therapies for meningiomas. Expert Rev Neurother 6: 1447-1464, 2006.

24. Fathallah-Shaykh HM, He B, Zhao LJ, Engelhard HH, Cerullo L, Lichtor T, Byrne R, Munoz L, Von Roenn K, Rosseau GL, Glick R, Sherman C and Farooq K: Genomic expression discovery predicts pathways and opposing functions behind phenotypes. J Biol Chem 278: 23830-23833, 2003.

25. Hanemann CO, Bartelt-Kirbach B, Diebold R, Kampchen K, Langmesser $\mathrm{S}$ and Utermark T: Differential gene expression between human schwannoma and control Schwann cells. Neuropathol Appl Neurobiol 32: 605-614, 2006.

26. Martinez-Glez V, Franco-Hernandez C and Rey JA: Microarray gene expression profiling in meningiomas and schwannomas. Curr Med Chem 15: 826-833, 2008.

27. Oh MK, Scoles DR, Haipek C, Strand AD, Gutmann DH Olson JM and Pulst SM: Genetic heterogeneity of stably transfected cell lines revealed by expression profiling with oligonucleotide microarrays. J Cell Biochem 90: 1068-1078, 2003.

28. Sayagues JM, Tabernero MD, Maillo A, Trelles O, Espinosa AB, Sarasquete ME, Merino M, Rasillo A, Vera JF, Santos-Briz A, de Alava E, Garcia-Macia MC and Orfao A: Microarray-based analysis of spinal versus intracranial meningiomas: different clinical, biological, and genetic characteristics associated with distinct patterns of gene expression. J Neuropathol Exp Neurol 65: 445-454, 2006

29. Watson MA, Gutmann DH, Peterson K, Chicoine MR, Kleinschmidt-DeMasters BK, Brown HG and Perry A: Molecular characterization of human meningiomas by gene expression profiling using high-density oligonucleotide microarrays. Am J Pathol 161: 665-672, 2002

30. Welling DB, Lasak JM, Akhmametyeva E, Ghaheri B and Chang LS: cDNA microarray analysis of vestibular schwannomas. Otol Neurotol 23: 736-748, 2002.
31. Wrobel G, Roerig P, Kokocinski F, Neben K, Hahn M, Reifenberger G and Lichter P: Microarray-based gene expression profiling of benign, atypical and anaplastic meningiomas identifies novel genes associated with meningioma progression. Int J Cancer 114: 249-256, 2005.

32. Canzian F, Salovaara R, Hemminki A, Kristo P, Chadwick RB, Aaltonen LA and de la Chapelle A: Semiautomated assessment of loss of heterozygosity and replication error in tumors. Cancer Res 56: 3331-3337, 1996.

33. Rouleau GA, Merel P, Lutchman M, Sanson M, Zucma J, Marineau C, Hoang-Xuan K, Demczuk S, Desmaze C, Plougastel $\mathrm{B}$, et al: Alteration in a new gene encoding a putative membrane-organizing protein causes neuro-fibromatosis type 2. Nature 363: 515-521, 1993.

34. Weber RG, Bostrom J, Wolter M, Baudis M, Collins VP, Reifenberger G and Lichter P: Analysis of genomic alterations in benign, atypical, and anaplastic meningiomas: toward a genetic model of meningioma progression. Proc Natl Acad Sci USA 94: 14719-14724, 1997

35. Kluwe L, Nygren AO, Errami A, Heinrich B, Matthies C, Tatagiba $\mathrm{M}$ and Mautner V: Screening for large mutations of the NF2 gene. Genes Chromosomes Cancer 42: 384-391, 2005.

36. Martinez-Glez V, Franco-Hernandez C, Lomas J, Pena-Granero C, de Campos JM, Isla A and Rey JA: Multiplex ligation-dependent probe amplification (MLPA) screening in meningioma. Cancer Genet Cytogenet 173: 170-172, 2007.

37. Pelz AF, Klawund P, Skalej M, Wieacker P, Kirches E, Schneider T and Mawrin C: Novel chromosomal aberrations in a recurrent malignant meningioma. Cancer Genet Cytogenet 174: 48-53, 2007.

38. Bostrom J, Cobbers JM, Wolter M, Tabatabai G, Weber RG, Lichter P, Collins VP and Reifenberger G: Mutation of the PTEN (MMAC1) tumor suppressor gene in a subset of glioblastomas but not in meningiomas with loss of chromosome arm 10q. Cancer Res 58: 29-33, 1998

39. Peters N, Wellenreuther R, Rollbrocker B, Hayashi Y, Meyer-Puttlitz B, Duerr EM, Lenartz D, Marsh DJ, Schramm J, Wiestler OD, Parsons R, Eng C and von Deimling A: Analysis of the PTEN gene in human meningiomas. Neuropathol Appl Neurobiol 24: 3-8, 1998

40. Lassaletta L, Bello MJ, Del Rio L, Alfonso C, Roda JM, Rey JA and Gavilan J: DNA methylation of multiple genes in vestibular schwannoma: relationship with clinical and radiological findings. Otol Neurotol 27: 1180-1185, 2006.

41. Boultwood J and Wainscoat JS: Gene silencing by DNA methylation in haematological malignancies. Br J Haematol 138: $3-11,2007$

42. Hesson LB, Cooper WN and Latif F: The role of RASSF1A methylation in cancer. Dis Markers 23: 73-87, 2007

43. Rosette C, Roth RB, Oeth P, Braun A, Kammerer S, Ekblom J and Denissenko MF: Role of ICAM1 in invasion of human breast cancer cells. Carcinogenesis 26: 943-950, 2005.

44. Kletsas D, Pratsinis H, Mariatos G, Zacharatos P and Gorgoulis VG: The proinflammatory phenotype of senescent cells: the p53-mediated ICAM-1 expression. Ann NY Acad Sci 1019: 330-332, 2004

45. Kondraganti S, Gondi CS, McCutcheon I, Dinh DH, Gujrati M, Rao JS and Olivero WC: RNAi-mediated downregulation of urokinase plasminogen activator and its receptor in human meningioma cells inhibits tumor invasion and growth. Int $\mathrm{J}$ Oncol 28: 1353-1360, 2006

46. Salajegheh M, Rudnicki A and Smith TW: Expression of urokinase-type plasminogen activator receptor (uPAR) in primary central nervous system neoplasms. Appl Immunohistochem Mol Morphol 13: 184-189, 2005.

47. McMahon GA, Petitclerc E, Stefansson S, Smith E, Wong MK, Westrick RJ, Ginsburg D, Brooks PC and Lawrence DA: Plasminogen activator inhibitor-1 regulates tumor growth and angiogenesis. J Biol Chem 276: 33964-33968, 2001.

48. Soff GA, Sanderowitz J, Gately S, Verrusio E, Weiss I, Brem S and Kwaan HC: Expression of plasminogen activator inhibitor type 1 by human prostate carcinoma cells inhibits primary tumor growth, tumor-associated angiogenesis, and metastasis to lung and liver in an athymic mouse model. J Clin Invest 96: 2593-2600, 1995.

49. Barbieri F, Bajetto A, Porcile C, Pattarozzi A, Massa A, Lunardi G, Zona G, Dorcaratto A, Ravetti JL, Spaziante R, Schettini G and Florio T: CXC receptor and chemokine expression in human meningioma: SDF1/CXCR4 signaling activates ERK1/2 and stimulates meningioma cell proliferation. Ann NY Acad Sci 1090: 332-343, 2006. 
50. Hiratsuka S, Minowa O, Kuno J, Noda T and Shibuya M: Flt-1 lacking the tyrosine kinase domain is sufficient for normal development and angiogenesis in mice. Proc Natl Acad Sci USA 95: 9349-9354, 1998.

51. Al Khalaf HH, Lach B, Allam A, AlKhani A, Alrokayan SA and Aboussekhra A: The p53/p21 DNA damage-signaling pathway is defective in most meningioma cells. J Neurooncol 83: 9-15, 2007.

52. Thyrell L, Hjortsberg L, Arulampalam V, Panaretakis T, Uhles S, Dagnell M, Zhivotovsky B, Leibiger I, Grander D and Pokrovskaja K: Interferon alpha-induced apoptosis in tumor cells is mediated through the phosphoinositide 3-kinase/ mammalian target of rapamycin signaling pathway. J Biol Chem 279: 24152-24162, 2004.

53. Wu S, Murrell GA and Wang Y: Interferon-alpha (Intron A) upregulates urokinase-type plasminogen activator receptor gene expression. Cancer Immunol Immunother 51: 248-254, 2002.

54. Siddique K, Yanamandra N, Gujrati M, Dinh D, Rao JS and Olivero W: Expression of matrix metalloproteinases, their inhibitors, and urokinase plasminogen activator in human meningiomas. Int J Oncol 22: 289-294, 2003.
55. Hrabec E, Naduk J, Strek M and Hrabec Z: Type IV collagenases (MMP-2 and MMP-9) and their substrates - intracellular proteins, hormones, cytokines, chemokines and their receptors. Postepy Biochem 53: 37-45, 2007.

56. Carvalho LH, Smirnov I, Baia GS, Modrusan Z, Smith JS, Jun P, Costello JF, McDermott MW, VandenBerg SR and Lal A: Molecular signatures define two main classes of meningiomas. Mol Cancer 6: 64, 2007.

57. Smith JS, Lal A, Harmon-Smith M, Bollen AW and McDermott MW: Association between absence of epidermal growth factor receptor immunoreactivity and poor prognosis in patients with atypical meningioma. J Neurosurg 106: 1034-1040, 2007.

58. Scoles DR, Qin Y, Nguyen V, Gutmann DH and Pulst SM: HRS inhibits EGF receptor signaling in the RT4 rat schwannoma cell line. Biochem Biophys Res Commun 335: 385-392, 2005.

59. Eswarakumar VP, Lax I and Schlessinger J: Cellular signaling by fibroblast growth factor receptors. Cytokine Growth Factor Rev 16: 139-149, 2005. 